\title{
Peran Pondok Pesantren Modern Gontor Sebagai Instrumen Multitrack Diplomacy Pendidikan dalam Kerjasama Internasional
}

\author{
Novi Amalia \\ Program Studi Hubungan Internasional, Universitas Darussalam Gontor - Indonesia \\ Email: novirizka@unida.gontor.ac.id \\ Diserahkan: 12 September 2019 | Diterima: 27 Desember 2019
}

\begin{abstract}
Islamic boarding schools are one of the educational institutions that are in great demand by many Muslims in Indonesia starting from the middle to lower classes of society to middle and upper society. The role of the pesantren in educating the younger generations in the millennial era has quite a lot of impact. The current phenomenon is that many education systems only prioritize school education in the classroom without understanding character education. One of the pesantren which is quite long and in demand and produces many alumni who are engaged in government and professional fields is Pondok Modern Darussalam Gontor (PMDG). PMDG is Islamic boarding schools which have considerable domestic and foreign cooperation. This pattern of diplomacy and cooperation will have an impact on the existence of PMDG in pesantren education. In globalization era, diplomacy involves not only the state but also non-state actors. Diplomacy Line 5 (Educational Pathway) have a main goal to advancing the education. Educational institution can influence the thinking of learners, moreover it can be seen that the cooperation carried out by the pesantren educational institutions are many from foreign institutions and even students who demand knowledge from many other countries.
\end{abstract}

Keywords: Pondok, Darussalam, Gontor, Diplomacy, Education.

\begin{abstract}
Abstrak
Pondok pesantren adalah salah satu institusi pendidikan yang sangat diminati oleh banyak Muslim di Indonesia mulai dari masyarakat kelas menengah ke bawah hingga masyarakat menengah ke atas. Peran pesantren dalam mendidik generasi muda di era milenial memiliki dampak yang cukup besar. Fenomena saat ini dapat dilihat dengan banyaknya sistem pendidikan hanya memprioritaskan pendidikan sekolah di kelas tanpa memahami pendidikan karakter. Salah satu pesantren yang cukup panjang dan menghasilkan banyak alumni yang bergerak di bidang pemerintahan dan profesional adalah Pondok Modern Darussalam Gontor (PMDG). PMDG merupakan pondok pesantren yang memiliki kerja sama dalam dan luar negeri yang cukup besar. Hal ini memengaruhi pola diplomasi yang nantinya akan berdampak pada keberadaan PMDG dalam pendidikan pesantren. Era globalisasi saat ini dibutuhkan sebuah bentuk diplomasi modern yang melibatkan tidak hanya negara tetapi juga aktor non-negara. Salah satunya adalah diplomasi pendidikan yang tujuan utamanya adalah untuk memajukan pendidikan. Sudut pandang lembaga pendidikan dapat memengaruhi pemikiran peserta didik, apalagi dilihat dari aspek kerjasama yang dilakukan oleh lembaga pendidikan pesantren lebih banyak dari lembaga asing dan bahkan siswa yang menuntut ilmu dari berbagai negara.
\end{abstract}

Kata kunci: Pondok, Darussalam, Gontor, Diplomacy, Education.

\section{PENDAHULUAN}

Dalam mengembangkan sumber daya manusianya, setiap negara memiliki sistem pendidikan yang

berbeda-beda. Hal tersebut 
dikarenakan perbedaan budaya dan pemikiran dari setiap negara tersebut. Indonesia sendiri memiliki sistem pendidikannya sendiri, di mana pendidikan di Indonesia terbagi menjadi lima tahap yaitu taman kanakkanak, sekolah dasar, sekolah menengah pertama, sekolah menengah atas dan perkuliahan. Sistem ini ditujukan untuk rakyat Indonesia dengan tujuan agar Indonesia dapat mengembangkan SDM-nya. Sehingga Indonesia dapat bersaing dengan negara-negara lain dan menjadi negara maju.

Apabila kita tinjau lebih jauh, terdapat suatu hal yang berbeda dengan pendidikan formal yang diterapkan pada negara-negara barat dan Timur Tengah. Di mana di negaranegara Asia Tenggara, terdapat suatu lembaga pendidikan yang didalamnya ditanamkan nilai-nilai Islam pada sistem pendidikan dan pengajarannya. lembaga tersebut biasa disebut dengan Pesantren. Pesantren adalah lembaga pendidikan Islam dengan sistem asrama dan didalamnya ada yang bertindak sebagai pendidik serta sentral figurnya adalah Kyai, Ajengan atau Guru, dan ada santri, asrama, ruang belajar serta masjid sebagai sentral kegiatannya. Di Indonesia, pesantren merupakan satu-satunya lembaga pendidikan di Indonesia yang dapat diterima dan memiliki basis yang kuat dalam kehidupan bangsa
Indonesia jauh sebelum penjajah Belanda datang dan mengenalkan sistem pendidikan modern pada abad ke 19-an (Hasbullah M., 2015).

Namun setelah kemerdekaan Indonesia, pendidikan Islam seperti halnya pesantren tidaklah langsung diterima dan dimasukkan dalam sistem pendidikan nasional. Pesantren tetap menjalankan pendidikan Islamnya dengan tidak terlalu diperhatikan oleh pemerintah. Pada tahun 1970-an, barulah pemerintah mulai unutk memperhatikan pendidikan Islam dengan adanya pembinaan madrasah dan pesantren-pesantren (Hasbullah M. 2015). Perhatian pemerintah tesebut dilanjutkan dengan dengan dibentuknya regulasi pendidikan diniyah dan pondok pesantren. Dimana Kementerian Agama mengeluarkan Peraturan Menteri Agama Republik Indonesia Nomor 18 Tahun 2014 Tentang Satuan Pendidikan Muadalah Pada Pondok Pesantren (Hasbullah M., 2015).

Seiring dengan kemajuan zaman, pesantren-pesantren di Indonesia menunjukkan perkembanganperkembangan dalam memperbarui sistem pendidikannya. Perkembangan yang dimaksud adalah banyak pesantren yang telah memasukkan kurikulum dari sistem pendidikan nasional sebagai kurikulum tetap mereka. Sehingga dapat dikatakan bahwa pesantren-pesantren tersebut 
telah bertransformasi kultur, sistem dan nilai-nilainya. Pesantren yang dulu disebut salafiyah (kuno), sekarang telah berubah menjadi khalafiyah (modern) (Mujib, 2006). Perubahan tersebut dapat kita liat dari sistem pengajaran yang menyerupai madrasah dan ada jenjang tingkatan pendidikan, adanya pengajaran pengetahuan umum di samping melanjutkan pengajaran pengetahuan agamanya, bertambahnya komponen pendidikan seperti halnya pendidikan keterampilan dan ekstrakulikuler dan pemberian ijazah sebagai tanda kelulusan bagi siswa yang telah menamatkan studinya di pesantren tersebut (Mujib, 2006). Jadi, dengan adanya perkembangan dan transformasi tersebut, kini pesantren bisa menjadi pilihan utama orang tua untuk menjalankan pendidikan bagi anak-anaknya.

Salah satu pesantren modern yang terkenal dengan sistem pendidikannya adalah PMDG. Berdiri sejak tahun 1926, PMDG telah banyak melakukan pengembangan dalam hal pendidikan dan pengajarannya. Sama seperrti pesantren-pesantren yang lainnya, PMDG pada mulanya juga merupakan pesantren salafiyah, namun pada tahun 1936 pimpinan PMDG memutuskan untuk menambah kata modern dalam nama pesantren Gontor. Hal tersebut diikuti dengan peresmian Kulliyyatul Mu'allimin AlIslamiyah (KMI) (Olman dan Nida',
2015). KMI adalah sistem pendidikan Islam yang modelnya hampir sama dengan sekolah normal Islam di Padang Panjang. Namun KMI mengkolaborasikan model tersebut dengan model pendidikan pesantren. Di mana proses pendidikan dan pengajaran dilakukan selama 24 jam di dalam pesantren tersebut. Pelajaranpelajaran agama dan umum diajarkan secara seimbang selama enam tahun dan pendidikan non akademik seperti halnya ekstrakurikuler melengkapi kegiatan santrinya pada waktu-waktu tertentu (Dahuri Olman, Fadlan Nida'. 2015). Sama seperti sistem-sistem pendidikan Islam yang lainnya, pada mulanya sistem KMI ini juga tidak banyak disetujui oleh masyarakat bahkan bertentangan dengan sistem pendidikan nasional. Namun seiring berjalannya waktu lebih tepatnya pada tahun 1998, ijazah lulusan KMI memperoleh pengakuan dari Kementerian Agama. Sedangkan pada tahun 2000, Kementerian Pendidikan dan Kebudayaan memberikan penyetaraan terhadap lulusan KMI dengan lulusan lembaga pendidikan nasional.

Selain sistem KMI, Salah satu bentuk pengembangan pendidikan PMDG adalah dengan adanya program kerjasama luar negeri dalam hal pendidikan. Negara-negara yang menjalin kerjasama dengan PMDG seperti halnya negara Timur Tengah 
yaitu Mesir, Arab Saudi, Sudan, Maroko, Qatar, Yordania, Kuwait. Sedangkan di negara bagian barat seperti halnya negara Inggris, Belanda, Turki, Perancis, Jerman serta di Asia seperti negara Malysia, Pakistan, Brunei Darussalam, Australia. Hal ini dilakukan dengan pertimbangan bahwa kerjasama luar negeri dapat mendorong kemajuan pendidikan di PMDG serta terdapat banyak manfaat yang didapat oleh PMDG dari kerjasama luar negeri tersebut.

Kerjasama ini juga dapat dikatakan sebagai diplomasi yang dilakukan oleh PMDG terhadap negara-negara luar untuk mencapai kepentingan diantara keduanya. Dalam Multi Track diplomasi, kerjasama antara PMDG dengan negara-negara luar ini dapat dikategorikan ke dalam track ke lima yaitu dalam bidang edukasi. Di mana track edukasi ini berguna dalam menyelenggarakan perdamaian dunia melalui pendidikan, pembelajaran serta penelitian (Diamond Louise, McDonald John Ambassador. 1996). Jadi, track kelima ini dilaksanakan dengan programprogram seperti halnya penelitianpenelitian terhadap suatu kasus yang dapat mengganggu kedamaian dunia. Sehingga dengan penelitian yang baik dan terpercaya, tidak akan ada informasi yang tidak benar tentang suatu kasus yang dapat merugikan suatu pihak.
Peran track kelima dalam multi track diplomasi ini sangatlah dibutuhkan karena dengan adanya track edukasi ini, setiap negara dapat memiliki pengetahuan tentang bagaimana cara untuk meredam konflik daiantara mereka. Terlebih lagi, dalam proses mengubah dunia untuk lebih maju, kita harus memulainya dengan memberikan pendidikan kepada masyarakat. Dengan adanya track kelima ini setiap negara memiliki kesempatan untuk memajukan mutu SDM mereka dengan adanya kerjasamkerjasama pendidikan antara negara satu dengan lainnya baik itu negara maju ataupun negara berkembang. Dalam tulisan ini penulis akan lebih membahas bagaimana peran dari PMDG dalam bekerjasam dengan luar negeri. Di mana kerjasam PMDG dengan luar negeri ini merupakan bentuk dari instrument multi track diplomacy ke lima yaitu diplomasi edukasi.

\section{METODE PENELITIAN}

Penelitian ini mencoba untuk menjelasakan tentang peran PMDG sebagai instrumen multi track diplomasi yaitu track ke lima edukasi. Oleh kerena itu, lingkup penelitian dalam tulisan ini adalah 1). Pondok Modern Darussalam Gontor, 2). Kerjasama yang dijalin oleh PMDG sebagai bentuk multi track diplomasi ke lima yaitu bidang edukasi. 
Selain itu, penulis akan menggunakan metode kualitatif deskriptif untuk menjelaskan pembahasannya. Dengan metode ini, penulis akan menjelaskan tentang pengaruh peran PMDG dalam menjalin kerjasama luar negeri dalam bidang edukasi terhadap perkembangan pendidikan di PMDG itu sendiri. Penulis akan melakukan pengamatan, pencarian, pengumpulan dan penafsiran data tentang topik terkait untuk menjawab rumusan masalah.

Dengan menggunakan metode kualitatif, maka akan terdapat dua bentuk data yaitu, data primer dan sekunder. Data primer merupakan wawancara, laporan, artikel, data dokumentasi, analisis data, surat kabar atau artikel majalah. Sedangkan data sekunder didapatkan dari artikel jurnal, buku, skripsi, situs resmi pemerintah, situs resmi instansi, dan lain-lain. Setelah data terkumpul, penulis menganalisis dan memprosesnya berdasarkan dengan pendekatan penelitian serta dilanjutkan dengan menyimpulkan hasil analisis data menggunakan teori penelitian.

\section{KERANGKA TEORI}

\section{Multi Track Diplomasi, Track 5: Edukasi}

Seperti yang kita ketahui bahwa setiap negara memiliki kepentingannya sendiri-sendiri dalam berhubungan dengan negara lain. Di mana kepentingan tersebut dapat berbuah kesepakatan daiantara mereka atau bahkan dapat menyebabkan konflik diantara pihak-pihak yang terkait. Oleh karena itu, terdapat suatu proses yaitu diplomasi yang dapat dijadikan terobosan agar perdamaian dunia tetap terjaga. Proses diplomasi sendiri dapat dibagi menjadi dua bentuk yaitu "Track One, Track Two". Di mana diplomasi Track One adalah diplomasi yang dilakukan dengan jalur antara pemerintahan negara. Sedangkan diplomasi Track Two adalah diplomasi yang dilakukan oleh aktor-aktor non pemerintah seperti halnya diplomasi antar individu, kelompok, pengusaha, dll. Lahirnya Track Two dalam diplomasi merupakan antisipasi dikarenakan dalam sebuah resolusi konflik, pemerintah atau negara tidak dapat berjalan sendiri, mereka membutuhkan aktor lain yang benarbenar memiliki pengetahuan dan kapabilitas dalam banyak bidang yang terkait dengan resolusi konflik tersebut (Dian Tonny Effendi. 2013).

Seiring berjalannya waktu, diplomasi yang dilakukan oleh aktor non pemerintah semakin berkembang dan diminati. Dimana hasil dalam menerapkan dilpomasi Track Two dapat disebut dengan Multi Track Diplomacy. Multi Track Diplomacy sendiri memiliki sembilam Track yang 
dapat digunakan dalam resolusi konflk. Sembilan track tersebut yaitu 1) government, non government/professional, 3) business, 4) privat citizen, 5) research, training, and education, 6) activism, 7) Religion, 8) Funding, 9) Communication and media (Diamond and McDonald, 1996).

Dalam penelitian ini, penulis akan membahas tentang peran PMDG sebagai instrumen dari Multi Track Diplomasi ke lima yaitu track edukasi dalam bekerjasama dengan negara lain di bidang edukasi. Sesuai dengan pembahasan tersebut, penulis akan lebih berfokus pada track ke lima dalam Multi Track Diplomasi. Di mana PMDG haruslah melakukan dilomasi edukasi mereka dalam bidang edukasi dengan negara-negara yang telah maju pendidikannya untuk mengembangkan pendidikan internal mereka. Selain itu, dengan adanya kerjasama ini, baik PMDG maupun negara yang bekerjasama dengannya memliki keuntungan masing-masing. Dimana keuntungan atau manfaat tesebut akan kita bahas dalam pembahasan tulisan ini.

\section{PEMBAHASAN}

Pendiri PMDG yaitu KH. Ahmad Sahal, KH. Zainuddin Fanani, dan KH. Imam Zarkasyi memiliki empat lembaga pendidikan luar negeri yang menjadi inspirasi dalam mendirikan dan menjalankan sistem PMDG. Keempat inspirasi tersebut adalah University of Al-Azhar Mesir yang telah berdiri selama ratusan tahun dan memiliki harta wakaf yang dapat membiayai beasiswa siswa seluruh dunia. Lalu di Mauratina terdapat pondok Syanggit yang dikelola dengan sistem keikhlasan dimana para pengasuh mendidik serta menanggung kebutuhan murid-muridnya siang dan malam. Setelah itu, di India terdapat University Muslim Aligarh, yaitu lembaga pendidikan modern yang membekali para mahasiswanya dengan ilmu pengetahuan modern dan agama. Inspirasi yang terakhir didapat dari Santiniketan University di daerah terpencil India, dimana para pendiri PMDG terinspirasi dari jiwa kesederhanaan para pendiri Santiniketan dan ketenangan serta kedamaian suasana pendidikan di sana (Olman dan Nida', 2015).

Dari keempat inspirasi tersebut, dapat kita lihat bahwa PMDG diatur untuk menjadi pesantren yang khalafiyah atau modern. Di mana didalamnya para pengasuh dan pendidik telah memadukan antara pendidikan agama dan juga pendidikan umum. Selain itu, pendidikan tersebut dilakukan selama 24 jam yang didasari oleh jiwa-jiwa keikhlasan dari para pendidik dan pengasuhnya. Di sisi lain, kita dapat menemukan suasana kedamaian, ketentraman serta 
ketenangan apabila berkunjung ke PMDG, hal ini dikarenakan para santri dan pengasuh disana mengusung asas ukhuwah Islamiyah dalam menjalin hubungan diantara mereka (Imam, 1993). Selain itu, kita juga dapat menyaksikan sebuah kesederhanaan yang sangat dijunjung tinggi dalam berkehidupan di PMDG, dimana arti dari kesedehanaan tersebut adalah penggunaan suatu kebutuhan oleh santri, pengasuh atau pemimpin pondok sesuai dengan kebutuhan mereka masing-masing. PMDG juga memiliki keistimewaan layaknya AlAzhar University Mesir, dimana PMDG sendiri merupakan bentuk wakaf dari Trimurti pendiri pondok kepada umat Islam yang abadi. PMDG sendiri diwakafkan oleh Trimurti agar ketika para Trimurti tersebut telah meninggal pondoknya tidak ikut meninggal juga. Namun terdapat pengasuh-pengasuh yang diamanati untuk meneruskan sesuai dengan ideide yang dikehendaki oleh Trimurti (Imam, 1993).

Apabila kita mengkaji sistem pendidikan PMDG, maka akan kita temukan sebuah pendidikan karakter yang diterapkan kepada santri-santri bahkan pengasuhnya sekalipun. Hal tersebut dapat kita lihat dari visi PMDG itu sendiri yaitu sebagai lembaga pendidikan pencetak kaderkader pemimpin umat, menjadi tempat ibadah talab al-'ilmi; dan menjadi sumber pengetahuan Islam, bahasa alQur'an, dan ilmu pengetahuan umum, dengan tetap berjiwa pesantren. Selain itu, PMDG juga memiliki misi yaitu membentuk generasi yang unggul menuju terbentuknya Khaira ummah, mendidik dan mengembangkan generasi mukmin-muslim yang berbudi tinggi, berbadan sehat, berpengetahuan luas, dan berpikiran bebas, serta berkhidmat kepada masyarakat mengajarkan ilmu pengetahuan agama dan umum secara seimbang menuju terbentuknya ulama yang intelek, mewujudkan warga negara yang berkepribadian Indonesia yang beriman dan bertakwa kepada Allah SWT (Gontor, 2019). Dengan adanya visi dan misi tersebut, PMDG menjadi salah satu lembaga pendidikan yang unggul dalam mencetak kaderkader pemimpin umat.

Dalam proses mengembangkan pendidikannya, PMDG juga melakukan program kerjasama di bidang pendidikan baik itu dengan lembaga dalam negeri maupun luar negeri. Program-program kerjasama dengan luar negeri tersebut didukung dengan diakuinya ijazah lulusan KMI atau lulusan PMDG oleh beberapa lembaga pendidikan internasional seperti halnya Universitas Al-Azhar dan Universitas Kairo di Mesir, Universitas Islam Madinah dan Universitas Ummul Quro Mekkah di Saudi Arabia, Universitas Islamabad, 
Universitas Aligarh dan Universitas Punjab Lahore di Pakistan, International Islamic University Kuala Lumpur dan University of Malaya di Malaysia (Olman dan Nida', 2015).

Kerjasama yang dilakukan oleh PMDG juga dapat dikatakan sebagai proses diplomasi, lebih tepatnya diplomasi Track Two yang dilakukan oleh aktor non pemerintah. Di mana dari diplomasi Track two tersebut, terlahir suatu konsep yang dinamakan Multi Track Diplomasi. Kerjasama PMDG diatas dapat dimasukkan kedalam bagian dari Multi Track Diplomasi Track yang ke lima yaitu diplomasi edukasi. Hal tersebut dikarenakan kerjasama di atas merupakan bentuk dari salah satu strategi PMDG untuk mengembangkan kemampuan santri. Sehingga dari tahun ke tahun PMDG dapat mencetak alumni-alumni yang ideal dengan taraf internasional dimana alumni-alumni yang berkualitas tersebut dapat menjadi SDM yang bermutu serta bisa mengembangkan Indonesia menjadi negara maju.

Keterlibatan Non-State Actor dalam kesuksesan kerjasama internasional sangat diperlukan. Salah satu aktor Non-State disini adalah instansi pendidikan pesantren yang notabene melakukan banyak kerjasama luar negeri baik dengan intansi pendidikan lain maupun dengan organisasi non negara. Dari kerjasamakerjasama yang dilakukan oleh Pondok Pesantren.

\section{Gambar 1. Bagan Kerjasama}

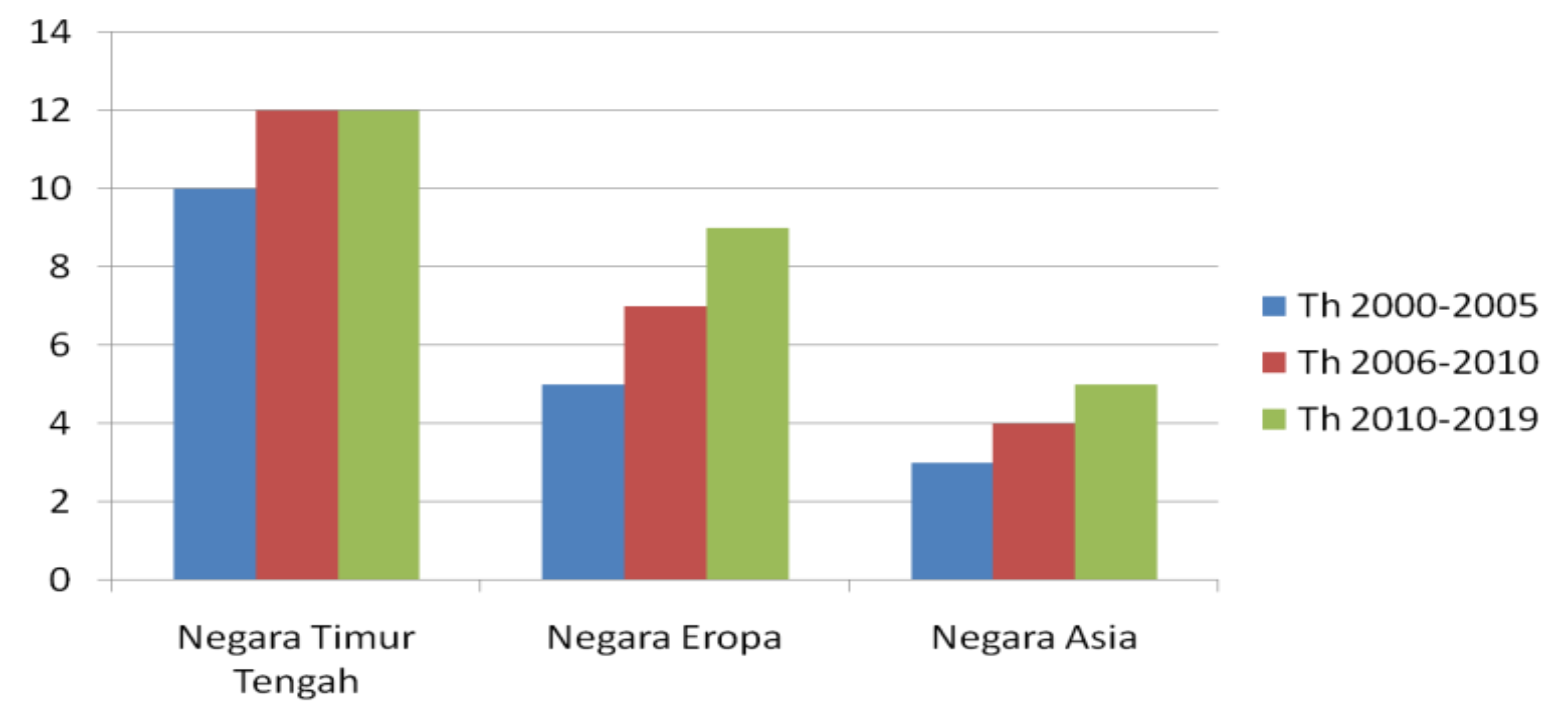

Sumber: bttp:/ / unida.gontor.ac.id/ international-networking/ 
Beberapa contoh implementasi kerjasama ini seperti halnya program pertukaran pelajar antara santri PMDG dan pelajar dari instansi luar negeri, adanya seminar-seminar internasional yang diisi oleh akademisi luar negeri dan membahas tentang isuisu internasional yang masih hangat, diberikannya beasiswa kepada alumnialumni PMDG untuk meneruskan pendidikannya di negara-negara yang menjalin kerjasama dengan PMDG, terdapat bantuan yang diberikan kepada PMDG baik dalam hal materil dan immaterial seperti halnya bantuan dana untuk pembangunan gedunggedung, terdapat juga bantuan berupa buku-buku yang dapat dipelajari oleh santri-santri. Implementasi ini juga dipermudah dengan hadirnya Universitas Darussalam Gontor (UNIDA) yang telah memiliki banyak MOU dengan lembaga-lembaga pendidkan di dalam maupun luar negeri. Dimana UNIDA yang merupakan Universitas milik Gontor telah melakukan banyak diplomasi dalam bidang edukasi. Hal ini dilakukan karena Pesantren memiliki dua tugas pokok yang harus diberikan kepada santri-santrinya seperti yang dikatakan oleh M. Natsir yaitu membina generasi Muslim, priawanita, untuk sanggup berkecimpung dan berkompetisi dalam masyarakat bagi pembinaan dan pembudayaan dunia ini di berbagai bidang, sementara itu mereka tidak putus hubungannya dengan Ilahi. Tugas selanjutnya adalah membina santri-santrinya untuk benarbenar mengerti tentang agama Islam.

Apabila kita analisa lebih jauh, diplomasi edukasi yang dilakukan oleh PMDG dengan cara menjalin kerjasama dalam bidang pendidikan dengan beberapa negara yang maju pendidikannya telah berhasil untuk meningkatkan mutu dan kualitas santrinya. Hal tersebut dapat dilihat dari banyaknya bantuan-bantuan yang dapat menambah fasilitas-fasilitas pendidikan santri, banyaknya alumnialumni yang telah melanjutkan studinya di luar negeri baik itu di negara-negara Barat, Timur Tengah bahkan di Asia. Selain itu, alumnialumni PMDG juga semakin mudah untuk bersaing dan masuk dalam hal pekerjaan baik itu di sektor instansiinstansi pemerintahan maupun non pemerintahan. Terlebih lagi, dengan adanya UNIDA dapat dijadikan basis dari penelitian-penelitian serta seminar-seminar tentang isu-isu internasional yang sedang hangat dibahas baik itu dilaksanakan di UNIDA ataupun di luar negeri. Disamping memiliki manfaat bagi PMDG, diplomasi ini juga bermanfaat bagi negara-negara yang menjalinnya seperti adanya penelitian-penelitian tentang pengembangan daerah-daerah ataupun penelitian yang berhubungan dengan negara mereka yang dilakukan 
oleh peserta pertukaran pelajar, bertambahya pelajar-pelajar luar negeri yang menuntut ilmu di negaranya karena adanya beasiswa yang diberikan.

\section{KESIMPULAN}

Diplomasi

pendidikan

merupakan sutau hal yang harus dilakukan oleh lembaga-lembaga pendidikan untuk lebih mengembangkan lagi mutu dan kualitas pendidikan mereka. Terlebih lagi lembaga pendidikan seperti pesantren yang merupakan salah satu lembaga pendidikan yang diminati orang tua wali murid pada saat ini. Seperti halnya pada kasus di tulisan ini, PMDG yang telah terkenal dengan sistem pendidikan yang dinamis, telah melaksanakan diplomasi edukasi dengan cara bekerjasama dengan negara-negara yang maju pendidikannya. Seperti halnya negara Timur Tengah yaitu Mesir, Arab Saudi, Sudan, Maroko, Qatar, Yordania, Kuwait. Sedangkan di negara bagian barat seperti halnya negara Inggris, Belanda, Turki, Perancis, Jerman serta di Asia seperti negara Malysia, Pakistan, Brunei Darussalam, Australia.

Diplomasi yang dilakukan oleh PMDG ini bisa dibilang berhasil dengan beberapa indikasi yang telah tercapai seperti halnya banyaknya bantuan-bantuan yang dapat menambah fasilitas-fasilitas pendidikan santri, banyaknya alumnialumni yang telah melanjutkan studinya di luar negeri baik itu di negara-negara Barat, Timur Tengah bahkan di Asia. Selain itu, alumnialumni PMDG juga semakin mudah untuk bersaing dan masuk dalam hal pekerjaan baik itu di sektor instansiinstansi pemerintahan maupun non pemerintahan. Terlebih lagi, dengan adanya UNIDA dapat dijadikan basis dari penelitian-penelitian serta seminar-seminar tentang isu-isu internasional yang sedang hangat dibahas baik itu dilaksanakan di UNIDA ataupun di luar negeri. Selain itu, diplomas iini juga memiliki efek baik bagi negara yang menjalin kerjasama tersebut seperti adanya penelitian-penelitian tentang pengembangan daerah-daerah ataupun penelitian yang berhubungan dengan negara mereka yang dilakukan oleh peserta pertukaran pelajar, bertambahya pelajar-pelajar luar negeri yang menuntut ilmu di negaranya karena adanya beasiswa yang diberikan. Oleh karena itu, mengapa diplomasi edukasi yang dilakukan oleh PMDG dapat dikatakan berhasil, karena telah berhasil untuk meningkatkan mutu dan kualitas santrinya serta bermanfaat bagi kedua belah pihak yang menjalin kerjasama pendidikan ini. 


\section{REFERENSI}

Diamond, Louise and McDonald, John Ambassador. (1996) Multi Track Diplomacy: A Systems Approach to Peace. Third edition. United States of America: Kumarian Press.

Effendi, Tonny Dian. (2013) “ASEAN Moslem Communityas Track-9 on Multitrack Diplomacy for The Conflict Resolution in Southeast Asia Region", Jurnal Hubungan Internasional, Vol. 2 No. 2.

Gontor (t.t) Selayang Pandang (Online). Tersedia di: https://www.gontor.ac.id/selayangpandang (Diakses: 1 September 2019).

Hasbullah M. (2015) Kebijakan Pendidikan dalam Perspektif Teori, Aplikasi dan Kondisi Objektif Di Indonesia. Depok: PT Rajagrafindo Persada.

Kemenag. (t.t) Regulasi Pendidikan Diniyah dan Pondok Pesantren. Jakarta: Direktorat Jendral Pendidikan Islam Kemenag RI.
Mujib, Abdul. (2006) Ilmu Pendidikan Islam. Edisi Pertama. Jakarta: Kencana Prenadamedia Group.

Natsir M. Pondok. (1970) Pesantren Kiai Ulama dengan Sejarah, Jasa dan Fungsinya dalam pembangunan Sebuah Antologi Kumpulan Pikiran dan Pendapat Tentang Pondok, Santri dan Kiai. Ponorogo: Institut Pendidikan Darussalam Pondok Modern Gontor.

Olman, Dahuri dan Nida', Fadlan. (2015) Pesantren-Pesantren Berpengarub di Indonesia. Surabaya: Penerbit Erlangga.

Zarkasyi, Imam. (1993) Pekan Perkenalan Pondok Modern Darussalam Gontor. Diktat Kuliah Umum Dalam Pekan Perkenalan. Ponorogo: Institut Pendidikan Darussalam Pondok Modern Gontor. 